\title{
Eu fui o que tu és, e tu serás o que sou ${ }^{1}$
}

\section{Um olhar fenomenológico-das narrativas em epitáfios I was what thou are, and thou shall be what I am}

\section{A phenomenological view of narratives in epitaphs}

\section{Por Míriam Cristina Carlos Silva, Tadeu Rodrigues luama e Vanessa Heidemann}

Ordens dos mortos

"Morrer de vida, viver de morte" - Heráclito

Este estudo parte de inquietações tecidas sob o diagnóstico de Norval Baitello Junior (2012) acerca da condição sedada que permeia a humanidade contemporaneamente, assim como da proposição de uma filosofia do levante, por Hakim Bey (2018), como modelo de contraposição à lógica de dominação - e, com isso, como crítica ao ideal de revolução, uma vez que Bey propõe, no lugar de uma revolução, um levante, já que o ideal de revolução representa uma proposta de permanência².

Para traçar um paralelo entre sedação e levante, buscamos observar possíveis narrativas contidas em epitáfios de um cemitério da cidade de Sorocaba, São Paulo.

Compreendemos a morte por seu viés cultural e consideramos os estudos de suas narrativas pertinentes à Comunicação. Segundo Morin (1997), a morte é o fundamento da cultura. O autor

\footnotetext{
1 Uma versão anterior deste trabalho foi apresentada durante o III Simpósio Internacional Comunicação e Cultura, promovido pela Universidade Municipal de São Caetano do Sul.

2 Para Bey (2018), a revolução estaria inserida em uma dinâmica de permutação de poder entre opressor e oprimido. Grosso modo, a revolução se configuraria como a busca do oprimido por tomar o lugar do opressor de maneira permanente. O levante, por sua vez, diz respeito à ruptura temporária dessa relação dialética. Justamente por não se pretender a permanência, os entusiastas do levante não seriam corrompidos pela possibilidade de se fazerem dominantes sobre outros.
} 


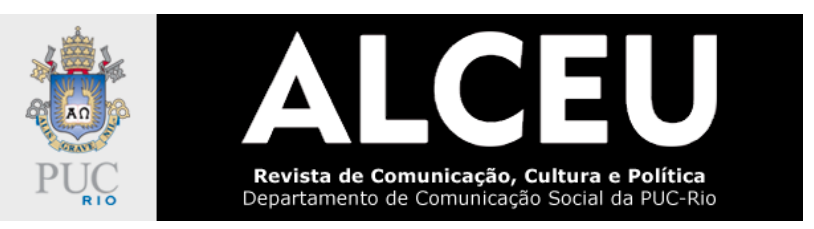

afirma que a consciência da nossa mortalidade cria uma segunda vida, na qual os mortos permanecem em relação com os vivos: aqueles que morreram são lembrados, cultuados e capazes de auxiliar ou até incomodar os que seguem vivendo. Também é a partir da consciência de nossa mortalidade que nascem deuses, mitos, ritos e tabus (MORIN, 1997). Acrescentamos à reflexão de Morin a ideia de que o fenômeno humano da morte nos auxilia a tecer narrativas, que são capazes de mediar tais experiências.

Para Vilém Flusser (2007), a necessidade de comunicação surge diante da consciência da condição mortal humana, um artifício para nos esquecermos dessa avassaladora solidão, contida na certeza de que nascemos e morreremos sozinhos. Isso posto, entendemos as narrativas da morte como formas comunicacionais, por sua capacidade não apenas de mediar, mas de nos levar a representar, criticar, interpretar e até transformar a experiência (SILVA; SANTOS, 2015).

Morin (1997) afirma que, para se entender a vida humana, é fundamental que entendamos a morte. Afirma ainda que a morte é amedrontadora e angustiante por significar o fim da individualidade, já que a morte de um indivíduo não significa nada para a espécie, mas que nossa individualidade perece na morte solitária, cuja insignificância para a continuidade da vida assombra e faz repensar as formas de viver. Dessa forma, as narrativas da morte são responsáveis por nos comunicar sobre a própria vida e por nos alertar sobre a brevidade do existir e a necessidade de celebrar cada experiência vivida.

Inquietamo-nos acerca de nossos rituais de sepultamento contemporâneos. Segundo Morin (1975), para muitos povos, o ritual do enterro era análogo ao ritual do plantio, um semear na terra para que a (pós-)vida vingasse. Podemos refletir sobre o ato simbólico de plantar o morto como a produção das narrativas pós-morte, das quais surgem histórias que irão eternizar o morto, fazendo com que os vivos se lembrem das histórias por ele vividas ou, ainda, permitindo que ele permaneça ativo, zelando, protegendo ou assombrando os que permanecem vivos. Porém, o ato de enterrar parece ter perdido seu sentido primeiro, substituído pelo cimentar cultural, este talvez igualmente esvaziado de significado. Com a assepsia do cimento e a informação concisa contida nas lápides, continuamos semeando as narrativas dos mortos?

Reiteramos que olhar para os rituais de morte e suas narrativas poderia fornecer-nos pistas para a compreensão da Comunicação, sobretudo quando observada enquanto fenômeno cultural, 
relativo ao impulso gregário dos seres humanos. Se a humanidade se faz no coletivo, e esse se funda pela nossa necessidade de sobrevivência, o que acontece quando a morte, a qual buscamos evitar quando nos juntamos em bando, é menosprezada, posta de lado?

"A morte é a sanção de tudo o que o narrador pode contar. É da morte que ele deriva sua autoridade", aconselha-nos Benjamin (1987, p. 208). As narrativas são estruturas de pensamento espaço-temporal cuja função é manter/transformar a cultura, assim como interpretar os mundos externo(s) e interno(s). É no momento e na lembrança da morte que toda a tradição é passada da velha para a nova geração. A nova geração, por sua vez, absorve o que é pertinente e delega o que é incabível naquele novo contexto. Se essa relação mortuária é apagada, a narrativa em si também teria sua potência diminuída.

Além disso, "a experiência que passa de pessoa a pessoa é a fonte a que recorreram todos os narradores" (BENJAMIN, 1987, p. 198). Nesse contexto que se apresenta, no qual a experiência que passa de pessoa a pessoa (ou dos outrora vivos para os agora viventes) nos parece estar esvaziada de sentido, pensamos ser relevante trazer à baila o convívio com a morte, rememorando nosso motivo ancestral de termos nos tornado seres comunicacionais e culturais.

Para buscar possíveis relações entre a sedação dos vivos e o levante dos mortos, por meio de seus epitáfios, realizamos uma pesquisa de campo no cemitério da Saudade, em Sorocaba, interior do estado de São Paulo. Os motivos para tal opção se devem tanto à questão geográfica (uma vez que residimos na cidade) quanto pela questão histórica/cultural (o cemitério, fundado em 1863, é o mais antigo do município). Encontra-se na área central, de maneira que figura entre os pontos de referência usuais, assim como é local de dormitório ${ }^{3}$ de importantes nomes na trajetória do município. Nosso percurso se dispõe a colocar nosso referencial teórico em diálogo, com o intuito de fornecer as bases que nos levaram a campo. A partir dessa proposta, nossa pesquisa se desdobra em uma visita ao cemitério no dia $1^{\circ}$ de abril de 2019 , no período da manhã, efetuada por dois dos três pesquisadores que colaboram neste artigo. A escolha da data, uma segunda-feira, foi motivada pela busca de sorver o cotidiano do local. Chegamos no cemitério aproximadamente às 8 horas da manhã e encerramos a visita por volta do meio-dia. Decorrente de nossas impressões dessa experiência, desenvolvemos um relato de caráter fenomenológico.

\footnotetext{
${ }^{3}$ Ressaltamos que cemitério tem origem no helênico koıнпти́рıov (koimeterion), literalmente dormitório.
} 


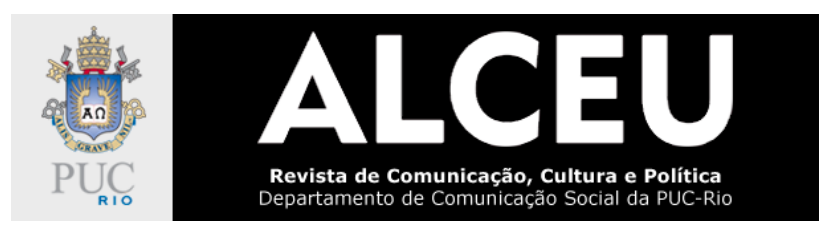

Para o método fenomenológico, a vivência singular é universalizada: pesquisadores e leitores da pesquisa podem compreendê-la porque são também participantes da condição humana. O que se busca, portanto, é uma descrição direta, intuitiva, da experiência baseada na observação, ainda assim sabendo que ela permite várias interpretações (MARTINEZ; SILVA, 2014, p. 6).

O motivo da adoção de tal perspectiva metodológica não é outro, senão a nossa impossibilidade 4 de alcançarmos as narrativas das vidas das pessoas ali sepultadas, restando-nos a reflexão ante nossas próprias epifanias, causadas pelos afetos de nossas experiências em tal ambiente, ou, ainda, a partir dos vestígios, índices que podem narrar algo sobre aqueles que jazem.

Tal opção metodológica se harmoniza com nosso posicionamento teórico, uma vez que advogamos a importância de reconhecer, e trazer à tona, a subjetividade dos pesquisadores em suas pesquisas. Sobretudo nas ciências humanas, a adoção de uma perspectiva puramente objetiva nos soa falaciosa. Mais profícuo, pensamos, seria adotar perspectivas teóricas, metodológicas e epistemológicas que abarquem a subjetividade, ainda que sem causar prejuízo ao rigor da pesquisa. Em resumo, assumimos que nem todo rigor precisa ser um rigor mortis. Ainda, entendemos o corpo como médium de acesso à experiência comunicacional. Um corpo que sente ao mesmo tempo em que raciocina. Transitar entre os corpos e suas histórias, com nosso próprio corpo, é uma forma privilegiada de experienciar o processo comunicacional mediado pelas narrativas dos epitáfios e também as narrativas do acaso, compostas pelo ambiente e pelos atores encontrados durante nossa visita.

\title{
Levante da Sedação
}

\author{
"Meu nome é Ozimândias, e sou Rei dos Reis: \\ Desesperai, ó Grandes, vendo as minhas obras!" \\ Nada subsiste ali. Em torno à derrocada \\ Da ruína colossal, areia ilimitada \\ Se estende ao longe, rasa, nua, abandonada." \\ - Percy Shelley
}

A nossa sociedade nos impulsiona para a sedação, ensinando como devemos nos comportar. Como aponta Baitello Junior (2012), aprendemos, desde a escola, a nos prostrarmos

\footnotetext{
${ }^{4}$ Compreendemos que, de fato, existe a possibilidade de efetuar tal levantamento, por meio de entrevistas com familiares, pesquisas em registros, dentre outros. Contudo, de maneira pragmática, uma vez que tais levantamentos não são o cerne de nossa proposta, o esforço de tal empreitada soa incompatível.
} 
rentes aos assentos de madeira, metal, plástico ou pedra. Ainda que muitas vezes esses assentos sejam desconfortáveis, permanecemos apaziguados sobre os próprios glúteos. Despendemos de boa parte de nosso tempo em assentos. Baitello Junior (2012, p. 15) indica:

Quantos anos de nossas vidas passamos todos sentados, em bancos escolares, assentos de templos religiosos, cadeiras no trabalho, diante de uma escrivaninha ou à frente de um computador, no cinema, no teatro ou similares, no ônibus, no trem, na bicicleta, no carro, nas cadeiras em torno de uma mesa (ah, e as famigeradas reuniões!) e, por fim, no sofá ou numa poltrona diante de uma máquina de imagens.

Deixar o corpo ser dominado, manter-se muitas vezes inerte em uma cadeira, contribui significativamente para que não só o corpo entre em um estado de letargia, mas para que também o pensamento passe pelo mesmo processo. O pensamento sentado "é uma operação que não permite surpresas, muito menos sobressaltos" (BAITELLO JUNIOR, 2012, p. 17).

Assim, manter-se prostrado sobre os glúteos inibe o desenvolvimento de um pensamento ativo, ou seja, com "a postura sentada pretende-se acalmar o animal inquieto e criativo, um verdadeiro vulcão pronto para entrar em erupção a qualquer momento" (BAITELLO JUNIOR, 2012, p. 18). Vulcão este que se mantém adormecido, anestesiado, impossibilitando os anseios nômades que a espécie humana carrega dentro de si, desde que desceu das árvores e caminhou em direção a diferentes horizontes.

Tanto a palavra sedar quanto sentar derivam do latim sedere, "que significa ao mesmo tempo, sentar e acalmar" (BAITELLO JUNIOR, 2012, p. 21). Aqueles que são convertidos e/ou seduzidos pela sedação seriam apáticos perante a vida. Desta maneira, podemos considerar que os sedentários representam a morte em vida, pois o ser vivo que não se coloca em movimento está fadado à atrofia.

Baitello Junior (2012) também aponta que o ser humano foge do nomadismo, renegando seus deuses do vento, ao buscar um lugar fechado e protegido, pois caminhar é encontrar-se com o desconhecido. Assim, "perante aos perigos e surpresas das jornadas perenes, o assentamento e a moradia fixa representavam, ao mesmo tempo, um entorno protetor e um aprisionamento opressivo" (BAITELLO JUNIOR, 2012, p. 47).

Bey (2018), por sua vez, aponta para a necessidade de experiências de ruptura que não visem a permanência. Pelo contrário: desprendida da necessidade de sobrevivência ante o tempo, é justamente na efemeridade que Bey aposta suas fichas. Por conta disso, ao contrário da definição 


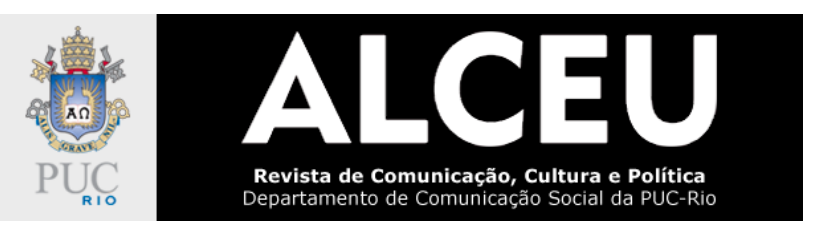

usual de levante como revolução malsucedida, o autor considera o levante como a condição de experiência pura que, justamente por não se pretender à duração, não dá oportunidade à traição de seus ideais.

Ao que Baitello Junior chama de sedação, corresponde a apatia, "um tédio saudável diante do Espetáculo desgastado" (BEY, 2018, p. 63). Ao levante de Bey, cabe o convite a "um exercício de pensar aos saltos" (BAITELLO JUNIOR, 2012, p. 15). Escolhemos dar a tal diálogo o nome de levante da sedação. Um convite para nos erguermos perante a sedação, mas, ao mesmo tempo, uma provocação contra as críticas que nada fazem (que se propõem a levantar, embora ainda permaneçam sedadas). O levante pressupõe insubordinação e ruptura.

Deste modo, cabe ao indivíduo que se preocupa em encontrar/criar tais rupturas envolverse com a invisibilidade, dada a necessidade de o levante passar despercebido diante das estruturas hegemônicas - uma ocupação que se faz pelas brechas, ou, como no modelo de semiosfera de luri Lotman, uma revolução que parte do periférico, no sentido de criar uma dinâmica de aproximação com o que está já consolidado (sedado), para operar a transformação. A partir de Lotman, entendemos que a cultura se aquece no contato com o novo, com o diverso (SILVA, 2010). Na semiosfera, um cosmo no qual pululam as práticas culturais, tudo o que segue para o centro e se consolida tende a se enrijecer, ao passo que, na periferia, o que está fora é incorporado, em um processo de tradução, dando vida ao novo. Cabe ressaltar que a ideia de centro e periferia, no contemporâneo, opera com entrelugares, pois não há um único centro, tampouco uma única periferia. Importa dizer que a cultura sobrevive da troca, dos processos de tradução.

Assim, a ressignificação do aparentemente insignificante desponta como tática para a percepção/criação de zonas autônomas temporárias: zonas nas quais cabe a ocupação de espaço, desprendida da necessidade de permanência, para que outras/novas perspectivas se apliquem sobre o grupo que se propõe a ocupá-las provisoriamente. Podemos somar à concepção de Bey a ideia de uma comunicação poética (SILVA, 2010), por se supor, no poético - considerado uma qualidade da linguagem e um modelo distinto de pensamento, que prevê a abertura -, a subversão do convencional, a polissemia e a insubordinação aos sentidos já estabelecidos socialmente.

Inspirados pela noção de que "a narrativa resta como esforço para ultrapassar a morte" (SILVA, 2018, p. 15), pensamos no epitáfio como uma tentativa sintética e poética de narrativizar a 


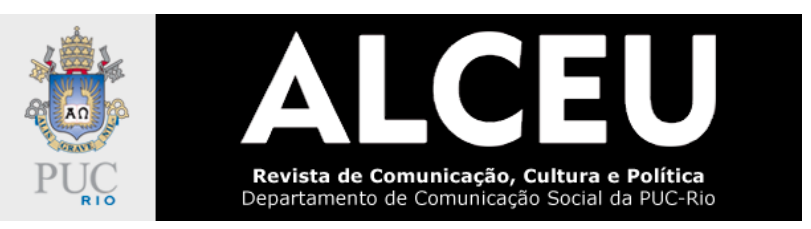

vida do morto, de modo que seja um chamado para o vivo levantar-se diante da sedação que permeia nosso viver, hipótese com a qual norteamos nosso estudo.

A narrativa, amparando-nos em Flusser (2007), pode ser vista como um artifício resultante da consciência da morte, uma forma de sobrevida. Trata-se, ainda, de uma forma para a compreensão dos fenômenos humanos, entre os quais a própria morte, e para organizar a experiência vivida ou contada por alguém em um relato que, quanto mais for poético, mais se torna poroso e capaz de produzir sensações. Esse parece ser o caso dos epitáfios, que sintetizam, em textos muito curtos, parte da narrativa de uma vida, como um último chamado dos mortos para os vivos.

A narrativa poética é um modo particular de se estabelecer uma comunicação poética. Ao contrário das formas que se preocupam com a exatidão, com a informação, com a precisão, com provas, a comunicação poética busca mobilizar a conversação por meio do sensível, da experiência sinestésica com o corpo, da polissemia, do erotismo (hiperbolização dos sentidos) e da ampliação das relações entre os fenômenos e sua mediação por meio das imagens, das metáforas (PICHIGUELLI; SILVA, 2017). O narrar poético é sustentado pelos efeitos sinestésicos da linguagem, pela atmosfera, pelo que provoca estesia.

Narrar a morte poeticamente é possibilitar aos vivos potencializar a sua sede de viver, ampliar o seu agir no mundo. Por outro lado, o mundo contemporâneo parece ter expulsado tanto a poesia quanto a morte, relegando-a aos hospitais, às funerárias, em uma assepsia que exclui do ser humano a oportunidade de pensar sobre o morrer a fim de reavaliar o que é estar vivo (MORIN, 1997). Sobretudo nas cidades mais economicamente desenvolvidas, sentimos que falta tempo para o luto, pois estamos ainda mais atrelados às cadeiras das reuniões, das escolas, dos carros e ônibus. Fixamo-nos em construções de concreto que muitas vezes inviabilizam enxergar o horizonte. $O$ trabalho engendraria o sedado (ou seria morto?) que vive (ou morre) para consumir as outras matérias (naturais ou não), enquanto o elixir da própria vida se esvai.

Sedação parece-nos sinônimo da morte em vida. Ao mesmo tempo, incomodamo-nos com a ideia de que talvez a vida sedada seja a vida que não é digna de um epitáfio. Afinal, poderia uma pessoa sedada legar algo aos vivos? Paradoxalmente, pensamos que sim. Afinal, a inexistência de uma provocação perpetuada na lápide não é, por si só, um convite à vida nômade? 


\section{A morte continua sustentando a vida}

"Enquanto viveres, brilha.

De todo não te aflijas,

Pois curta é a vida

E o tempo cobra seu tributo"

- Epitáfio de Sícilo

Elegemos o relato como forma de organizar a experiência vivenciada por meio da perspectiva fenomenológica. Trata-se de uma forma possível de mediar as percepções que obtivemos em campo. No dia $1^{\circ}$ de abril de 2019 , visitamos, no período da manhã, o cemitério da Saudade, localizado na região central da cidade de Sorocaba-SP. Do lado de dentro do portão principal, havia um homem entregando pedaços de papel com seu contato, panfletando seus serviços, que consistem na realização da manutenção dos túmulos. Decidimos ir até o final da rua principal do cemitério olhando, de maneira geral, para os epitáfios, para na volta pararmos naquelas lápides que nos chamavam a atenção. Durante o percurso, passamos por outro vendedor que estava atendendo clientes; sua frase nos inquietou: Põe uma cruz de pedra. Fica bom e ninguém rouba.

Nesse aspecto, o primeiro impacto em relação ao lugar não foi ligado às narrativas dos mortos, mas sim à presença daquelas pessoas que, a partir da morte dos outros, encontraram uma maneira de sustentar a própria vida.

O cemitério da Saudade é o mais antigo da cidade de Sorocaba e há um amontoado de túmulos, o que exige certa estratégia para o deslocamento do visitante. Alguns túmulos são praticamente inacessíveis, enquanto outros exigem um tortuoso malabarismo para que sejam alcançados.

Logo de partida, fica evidente que a hipótese de que encontraríamos algum tipo de mensagem dos mortos para os vivos, na forma dos epitáfios, não condizia com a realidade do local, já que muitas das mensagens estavam ilegíveis e boa parte delas eram mensagens dos vivos para os mortos, frases de lamento em relação à perda do ente, tais como sentiremos saudade ou saudades eternas. Espalhadas por todo o cemitério, observamos frases semelhantes, denotando 
que ali estavam frases prontas, que davam a sensação de transmitir sentimentos genéricos ou, ainda, de reforçar a anestesia dos vivos diante da vida e da morte. Como se a informação concisa e pronta pudesse dar conta de expressar uma vida que se foi e sua relação com os que ficaram. A informação que parece, como já debatido por Benjamin (1987), matar a própria narrativa. Nada havia de novo, surpreendente ou mesmo de poético.

Dentre todas as lápides que observamos, uma mensagem nos chamou a atenção:

Nascer
Viver
Morrer
Renascer
De novo
E progredir
Continuamente
Tal é a lei

Esses dizeres são a versão traduzida da mensagem encontrada no túmulo de Allan Kardec (1804-1869), sepultado no cemitério Père-Lachaise, em Paris. Dentre todos os epitáfios observados, este nos pareceu ser tanto uma mensagem dos mortos para os vivos, quanto dos vivos para os mortos. Pareceu, ainda, um poema concreto, perante as frases prontas observadas nos demais jazigos, denotando a sucessividade da vida, que sempre renasce, de novo, e progride, ininterruptamente, transformando-se. Trata-se de uma constatação de que os ciclos são a única permanência possível. A lei é a da continuidade, da impermanência e da permanente mudança entre os estados de vida e morte.

O abandono dos jazigos era evidente: muitos estavam quebrados, alguns não eram identificados pelo nome, e sim por um número. Em outros casos, nem mesmo isso era visto. Em um deles, a placa contendo o nome da pessoa caiu virada para baixo, impossibilitando sua identificação. Nesse aspecto, no decorrer do trajeto, cogitamos que o abandono da vida remete ao abandono da morte. Mas talvez seja o oposto, o abandono da morte denota o abandono da vida. São indícios de uma narrativa possível de ser construída para além dos epitáfios, mas no conjunto que representam as sugestões ofertadas pelo ambiente e pelos sujeitos vivos que transitam pelo cemitério. 


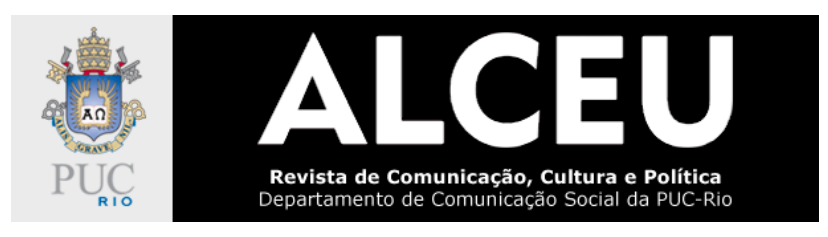

Quando esquecemos os nossos mortos, esquecemos o nosso passado. Quem são aquelas pessoas? O que elas fizeram? O passado que construiu o presente é importante? Consideramos que o legado dos mortos, em seus dormitórios perpétuos, é o de causar desconforto ao sedado, uma provocação e, em última instância, um chamado à vida ou à rememoração, na esteira de Benjamin (1987), pela evocação de imagens que os rastros dos mortos podem produzir. Entretanto, quem olha para a sombra da morte se ela foi cimentada em jazigos que jazem esquecidos?

Observamos um comportamento compartilhado por aqueles que estavam no cemitério naquela manhã (comerciantes, clientes, funcionários, um devoto atendendo pessoas, homens alcoolizados e idosos): um tom de voz baixo em suas conversas, ou mesmo caminhar em silêncio. Perante essa percepção, concluímos que as pessoas que visitaram o cemitério naquele dia, ao mesmo tempo que mantinham o silêncio, pareciam ignorar o esquecimento da manutenção das lápides.

Durante nossas idas e vindas, encontramos perto do portão principal uma lápide que chamou nossa atenção pela beleza das esculturas. Enquanto estávamos observando as imagens, um homem nos abordou. Ele não vestia camisa, segurando-a em suas mãos, com o rosto molhado, um pedaço de madeira, uma sacola e uma garrafa de aguardente. Visivelmente alcoolizado, perguntou se a lápide era de alguém da nossa família. Ao respondermos que não, e que estávamos apenas observando as esculturas, ele nos contou que também gostava de observar as esculturas e a beleza contida nelas.

Perguntou se conhecíamos as outras lápides e se sabíamos quem estava enterrado embaixo do chapéu de praia (nome popular de uma árvore). Ao receber uma negativa, explicou-nos que se tratava de um pracinha ${ }^{5}$ da cidade e perguntou se nós sabíamos quem era. Após citar alguns outros nomes, ouviu outro rapaz (também alcoolizado) o chamando e gritou de volta: quem está me chamando? Você já foi tomar o passe?; e logo se afastou.

O cemitério da Saudade também é o lugar de repouso de João de Camargo ${ }^{6}$, místico conhecido na cidade de Sorocaba por ter realizado milagres. Quando passamos por seu túmulo,

\footnotetext{
5 Termo geralmente utilizado para designar os soldados veteranos da segunda guerra mundial, formalmente conhecidos como Força Expedicionária Brasileira.

${ }^{6}$ Para um aprofundamento sobre João de Camargo, assim como sobre as representações midiáticas feitas a partir de sua memória, recomendamos a leitura da dissertação $A$ representação da estrutura narrativa mítica na vida real e representação fílmica: Cafundó (PROENÇA, 2014).
} 
que remete à capela onde viveu, percebemos que havia um devoto atendendo pessoas, uma espécie de médium, a perpetuar a vida do místico e, por meio de seu corpo, colocá-lo em contato com os vivos. Foi nesse local que os homens receberam o passe ${ }^{7}$.

O homem que nos abordou pareceu ser um tipo de guardião da memória de parte dos mortos do lugar, por oferecer narrativas (sejam estas ouvidas de outros, aprendidas por meio da história cultural da cidade ou mesmo inventadas por ele) de suas identidades. Além da nossa presença, havia comerciantes de lápides e homens alcoolizados. Nesse aspecto, aquele que estava sedado pela aguardente era quem aparentemente conhecia, rememorava ou, talvez, narrava sobre a história dos eternamente sedados.

Considerávamos que os epitáfios poderiam possibilitar uma epifania, com a narrativa dos mortos para aqueles que ainda podem caminhar. Contudo, se existem narrativas, essas são as que podemos construir a partir da observação do esquecimento daqueles que jazem entre os escombros, aos quais muitas vezes é negado o registro mais básico de sua existência, seus próprios nomes. Ou, ainda, dos vivos que perambulam pelo lugar, talvez tão esquecidos quanto os mortos ali sepultados.

\section{Sementes ao vento}

"Eu sou a boca escancarada Que draga sua carne

E que nunca poderá descansar Até que minha morte esteja escrita Em uma pedra que não se quebre" - Diamanda Galás

Nossa hipótese inicial era a de que os epitáfios seriam uma tentativa de narrativizar, em apenas um texto conciso, a memória das diversas experiências que permeiam a vida de uma pessoa. Entretanto, nos deparamos com memórias apagadas e esquecidas. As mensagens, quando visíveis, reproduziam frases feitas, por vezes genéricas, principalmente sobre a saudade que os vivos sentiriam de seus mortos.

\footnotetext{
7 De maneira superficial e sintética, o termo passe remete à imposição de mãos que visa promover cura ou conceder bênção.
} 


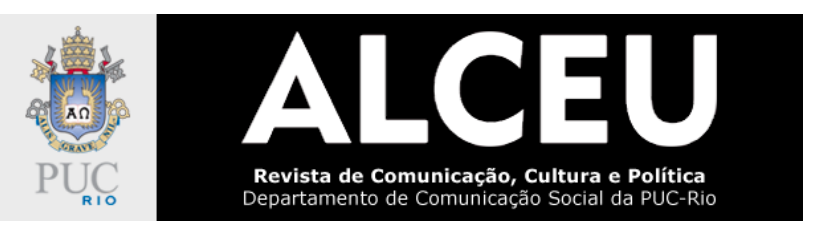

Ainda assim, o cemitério pareceu-nos convidativo ao surgimento de Zonas Autônomas Temporárias, pois é um lugar visível no centro da cidade, rodeado por estabelecimentos comerciais; e, ao mesmo tempo, despercebido dos transeuntes, abriga uma existência autônoma, que percebemos como alheia ao cotidiano externo.

É um lugar transitório para os vivos que nele ingressam, porém quem são essas pessoas? No dia $1^{\circ}$ de abril de 2019 , os vivos que cruzaram seus portões foram os comerciantes, alguns clientes, funcionários do local, um devoto atendendo pessoas, homens alcoolizados, alguns idosos e dois pesquisadores.

Se o cotidiano promove a sedação e o assentamento do pensamento, caminhar entre a sedação máxima que é a morte e a sedação transitória do álcool de nosso interlocutor nos causou saltos.

Se não encontramos nos epitáfios as narrativas dos mortos que convidam ao viver, encontramos na experiência de caminhar entre os mortos uma insurreição ante a inevitabilidade da finitude humana. Por fim, narrar nos parece continuar sendo sobre/viver.

Ainda que o esquecimento seja um derradeiro chamado para a negação da morte em vida, o cemitério possibilita olhar para o passado que, mesmo que representado por borrões de frases semiapagadas, carrega em si não o poder da carne, mas o poder dos ossos.

Esses ossos nos convidam a caminhar entre eles, a desvendar seus mistérios nos lembrando de que nosso fim será o mesmo. O chamado dos ossos é um chamado para o levante, para o movimento. Esse chamado provoca e indica que devemos deixar nossas narrativas para os vivos em vida, para que estes possam registrar em nossos epitáfios um pequeno fragmento de quem éramos. Concluímos que, ainda que abandonados, os mortos e seus rastros têm muito a nos comunicar sobre a vida.

Perguntamo-nos, por fim: cabe aos vivos recusar tais ordens dos mortos?

Míriam Cristina Carlos Silva Universidade de Sorocaba Doutora em Comunicação e Semiótica pela Pontifícia Universidade Católica de São Paulo ORCID: 0000-0002-6162-332X E-mail:miriam.silva@prof.uniso.br 
Tadeu Rodrigues luama

Centro Universitário Belas Artes Mestre em Comunicação e Cultura pela Universidade de Sorocaba

ORCID: 0000-0001-9875-2208

E-mail: tadeu.iuama@belasartes.br

Vanessa Heidemann

Universidade de Sorocaba

Mestra em Comunicação e Cultura pela Universidade de Sorocaba

ORCID: 0000-0002-4775-1827

E-mail:vheidemann@gmail.com

Recebido em: 29 de abril de 2020

Aprovado em: 21 de maio de 2020.

\section{Referências}

BAITELLO JUNIOR, N. O pensamento sentado: sobre glúteos, cadeiras e imagens. São Leopoldo: Editora Unisinos, 2012.

BENJAMIN, W. O narrador. Considerações sobre a obra de Nikolai Leskov. In: arte e política. Obras escolhidas, v. 1. São Paulo: Brasiliense, 1987, p. 197-221. Magia e técnica,

BEY, H. TAZ - Zona Autônoma Temporária. São Paulo: Veneta, 2018.

FLUSSER, V. O mundo codificado. São Paulo: Cosac \& Naify, 2007.

MARTINEZ, M.; SILVA, P. C. da. Fenomenologia: uso como método em educação. E-Compós (Brasília), v. 17, n. 2, 2014. p. 1-15. Disponível em: <https://bit.ly/2Xdqz9E>. Acesso em: 28 mai. 2020.

MORIN, E. O paradigma perdido. Rio de Janeiro: Zahar, 1975.

. O homem e a morte. Rio de Janeiro: Imago, 1997.

PICHIGUELLI, I; SILVA, M. C. C. Comunicação, poesia e o religare. Revista Comunicologia (Brasília), v. 10, p. 3-18, 2017. Disponível em: <https://bit.ly/2OC1qQF>. Acesso em: 23 nov. 2019.

PROENÇA, R. M. G. de. A representação da estrutura narrativa mítica na vida real e representação fílmica: Cafundó. Dissertação (Mestrado em Comunicação e Cultura) - Universidade de Sorocaba. Sorocaba, 2014. Disponível em: <https://bit.ly/2nRjvjY>. Acesso em: 30 set. 2019.

SILVA, M. C. C. Contribuições de luri Lotman para a Comunicação: Sobre a complexidade do signo poético. In: FERREIRA, G. M. (Org.). Teorias da Comunicação: Trajetórias Investigativas. Porto Alegre: EdiPUCRS, 2010. 
. Representações Poéticas da Morte nas Narrativas Midiáticas: Um Conto Chinês. Famecos, Porto Alegre, v. 25, n. 2, mai. 2018. Disponível em: <https://bit.ly/2DX8BOb>. Acesso em: 01 abr. 2019.

; SANTOS, T. C. Peregrinação, experiência e sentidos: Uma leitura de narrativas sobre o Caminho de Santiago de Compostela. E-Compós (Brasília), v.18, p.1-15, 2015. Disponível em: <https://bit.ly/33gmfGq>. Acesso em: 23 nov. 2019.

\section{Resumo}

Amparados pelo diagnóstico de Baitello Junior sobre a condição sedada do humano, compreendemos que uma vida sedada pressupõe a pobreza da experiência, consequentemente, a dificuldade em registrar/construir as memórias. Com a finalidade de identificar a existência de Zonas Autônomas Temporárias, consideradas como eventuais brechas na lógica da sedação, por meio da perspectiva fenomenológica, visitamos um cemitério em Sorocaba-SP, a fim de experimentar narrativas contidas em epitáfios. Partimos da premissa de que os epitáfios são uma tentativa de narrativizar de forma concisa as diversas experiências que compuseram a vida de alguém. As narrativas encontradas expuseram o abandono dos mortos, a repetição de frases feitas e a quebra da expectativa na relação narrativas imaginadas e narrativas encontradas pelos autores do texto.

Palavras-chave: Comunicação. Sedação. Zona Autônoma Temporária. Narrativa. Epitáfio.

\section{Abstract}

Supported by Baitello Junior's diagnosis about the sedated condition of the human, we understand that a sedated life presupposes the poverty of experience, consequently, the difficulty in registering/constructing memories. In order to identify the existence of Temporary Autonomous Zones, considered as possible loopholes in the logic of sedation, through the phenomenological perspective, we visited a cemetery in Sorocaba-SP, in order to experience narratives contained in epitaphs. We start from the premise that epitaphs are an attempt to narrate, concisely, the diverse experiences that made up someone's life. The narratives found exposed the abandonment of the dead, the repetition of jargon and the breaking of expectations in the relation between imagined narratives and narratives found by the authors of the text.

Keywords: Communication. Sedation. Temporary Autonomous Zone. Narrative. Epitaph.

\section{Resumen}

Con el apoyo del diagnóstico de Baitello Junior acerca de la condición sedada del ser humano, entendemos que una vida sedada presupone la pobreza de experiencia, en consecuencia, la dificultad para registrar/construir recuerdos. Para identificar la existencia de Zonas Autónomas Temporales, consideradas como posibles lagunas en la lógica de la sedación, a través de la perspectiva fenomenológica, visitamos un cementerio en Sorocaba-SP, para experimentar narrativas contenidas en epitafios. Partimos de la premisa de que los epitafios son un intento de narrar de manera concisa las diversas experiencias que conformaron la vida de alguien. Las narraciones encontradas expusieron el abandono de los muertos, la repetición de frases hechas y la ruptura de expectativas en la relación entre narraciones imaginarias y narrativas encontradas por los autores del texto.

Palabras clave: Comunicación. Sedación. Zona temporalmente autónoma. Narrativa. Epitafio. 